\title{
O Manual escolar como guarda-comidas, ou um processo de trofalaxia
}

Fernando José Monteiro da Costa

CITCEM - Centro de Investigação Transdisciplinar "Cultura, Espaço e Memória"/FLUP, Portugal. fjmcosta@iol.pt

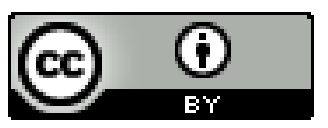

Educação: teoria e prática, Rio Claro, SP, Brasil - elSSN: 1981-8106

Está licenciada sob Licença Creative Common

\section{Resumo}

O manual escolar revela-se, sem dúvida hoje, um dispositivo que realiza percursos essenciais, numa espécie de quadrangulação, entre professores, alunos, encarregados de educação e editores. Como dispositivo privilegiado de educação, o ME assume, então, uma vitalidade que lhe confere um lugar especial junto dos docentes, mas envolvendo-se num intrincado circuito comercial, que lhe pode retirar essencialidade no ato educativo. Devendo constituir o ME um organizador avançado, a sua construção não deveria ser na base de instruções ou na perspetiva de que, se se tornar rotina, isso facilitaria a aquisição das aprendizagens. A construção do ME deve equacionar a legitimidade do outro, o aluno, e só fará sentido se considerar esse outro como consumidor, produtor, construtor, gestor e seu apreciador. Desta análise, pode resultar uma aproximação teórico-prática à construção de manuais escolares, mesmo considerando-se a análise empírica adoptada como método de investigação, base essencial, de modo, o ME possa adquirir uma dignidade elevada e consistente, na premissa de que deve contribuir, também, para a dignidade e consistência do conhecimento a adquirir pelos alunos.

Palavras-chave: Manual Escolar. Dispositivo de Educação. Controlo. Aprendizagem.

\section{The school manual as meat-safe, or a vomit process}

\begin{abstract}
The textbook is revealed, no doubt today, a device that performs essential pathways, a kind of quadrangulation, including teachers, students, parents and publishers. As a privileged device education, ME assumes, then, a vitality which gives it a special place among the teachers, but engaging in an intricate supply chain, we can remove the essentiality educational act. Should be the ME an organizer advanced, its construction should not be the basis of instructions or on the view that, if it becomes routine, it would facilitate the acquisition of learning. The construction of ME should consider the legitimacy of the other,
\end{abstract}


the student, and it will only make sense to consider this as consumer, producer, builder, manager and her lover. This review may result in a theoretical and practical approach to the construction of textbooks, even considering the empirical analysis, as a research method adopted, essential basis, so the ME can acquire a dignity consistently high, on the premise that should, also, contribute to the dignity and consistency of the knowledge acquired by students.

Keywords: Textbook. Device Education. Control. Learning.

\section{PROÉMIO}

O valor educativo de um manual escolar não pode deixar de ser considerado, pese embora, as opiniões divergentes sobre a sua importância e utilização na sala de aula. Tem gerado, claramente, indiscutível confronto teórico, diversos postulados sobre a sua construção, mas sempre na perspetiva de educação formal. E este tem sido, provavelmente, o maior erro de toda a análise efetuada até ao presente, pois deixa de fora considerações e critérios que podiam transformar o ME num autêntico livro, onde o pensamnto crítico, 0 espírito de invenção ou ainda, a penetração de juízos, fariam dele um arquivo de conhecimentos e experiências.

As discussões têm-se mantido, julgamos nós, num plano de superioridade subjetiva, por grupos ou individualidades, que deveriam abdicar de ideias preconcebidas, não confundindo desejo com realidade. De facto, esta discussão tem sido difícil afastada do contexto escolar e, portanto, sempre a ela subjugada e condicionada. Em suma, dever-se-ia adoptar uma atitude mais científica e menos teórica sob o ponto de vista operacional do ME. E depois, a análise da manualística vem misturada com um certo negócio editorial, quadro lamentável que prejudica o valor de qualquer abordagem sistémica. Será necessário enveredarmos por um espírito de investigação aberto, claridivente, empreendedor e livre de todo o tipo de rotina, que, aliás, se verifica na produção de um ME. Mas este tipo de colaboração, entre autores e editores, entre associações profissionais e encarregados de educação, entre escolas de ensino regular e as de formação de professores, entre investigadores e analistas, deveria constituir a estratégia de desenvolvimento, mas "os pesquisadores fecham-se frequentemente na sua torre de marfim, ignorando ou simulando ignorar o que os outros fazem" (PLANCHARD, 1974, p. 171). 
Normalmente, os professores estão arredados dos atos investigativos, ou por não estarem preparados, ou por não terem tempo disponível, ou porque, simplesmente, acham que isso é tarefa de outros, considerando Planchard (1974, p.177) que "seria errado estabelecer uma separação nítida entre a função docente e a função investigadora". E a produção de manuais escolares deveria absorver as diferentes experiências, os resultados das teses que se vêm acumulando num circuito universitário e aquilo que a atividade docente produz, em termos pedagógicos e didáticos, acrescido às expriências em sala de aula. Planchard lembra que a atitude científica adquire-se pelo exercício e que "há tantas observações e documentos que um professor poderia recolher no decorrer do seu contacto quotidiano com os alunos" (PLANCHARD, 1974, p. 178), pelo que a construção de um ME deveria acolher, igualmente, todas aquelas contribuições que, na prática, se verifica não existirem, resultando, então, um ME mais pobre, menos esclarecido, unilateral e, por fim, dispensável.

Edward Thorndike, para a elaboração de um manual escolar, a fim, de determinar quais os conteúdos mais importantes a incluir, passou por algumas escolas, convidando os alunos a fazerem-lhe perguntas, cujas respostas os interessassem verdadeiramente. Assim, pode concluir dos interesses escolares, tendo tido em conta o critério psicológico (o interesse das crianças) e o critério sociológico (relação com a vida corrente). Em sede de outros artigos e mesmo, no âmbito da minha tese de doutoramento ${ }^{1}$, tenho apresentado este assunto à discussão, porque me parece que um ME deve ser examinado fora do paradigma em que ele se inscreve, afastado da sua prática rotineira, de modo, se consiga, por um exercício de distanciamento, traçar linhas de investigação diferentes daquelas que têm regulado a conceção manualística escolar. Em distintas ocasiões, tenho advogado que deverão ser as próprias escolas a produzir os seus recursos didáticos, entre os que se destacam os manuais escolares, por estarem mais próximas das experiências e porque será mais fácil a recolha e registo das reações dos alunos, espécimenes de escrita, de exercícios, de desenhos, o que, curiosamente, Planchard (1974, p.178) não deixa de considerar que se insistiu "durante a formação de professores, sobre a necessidade da observação e da experimentação, mas não os iniciaram, suficientemente, em observar e experimentar".

\footnotetext{
${ }^{1}$ DA CAPO AL CODA, manualística de Educação Musical em Portugal (1967-2004): configurações, funções, organziação (2011)
} 
A utilização em exagero, o que se verifica cada vez mais, do ME, leva a uma atitude livresca, portanto a um ensino verbal e dogmático, que pode prolongar-se tempo fora da escolaridade, quando a obrigação da escola e dos professores, seria a de traçar linhas de indagação, de necessidade de se trabalhar com a vida e não fora dela, compilando trabalhos, analisando questões, consultando fundos documentais diversos, questionando Planchard se, neste caso, "não seria, afinal, um resultado animador e uma linha de conduta a manter?" (1974, p. 184).

\section{$2 \quad$ Transfert de Aprendizagem}

O ME nunca deixou de ser um artefacto tecnológico, na medida em que se trata de um objecto concebido e construído por seres humanos, com a finalidade de se rendibilizar e, porque não, automatizar os alunos nas suas tarefas quotidianas de escolaridade. Ele é concebido numa perspetiva de simplificação e de sumariação dos conteúdos escolares, respeitando o currículo oficial e, raramente, partindo para uma incursão num universo interdisciplinar. Etimologicamente, manual é um dispositivo que ajuda a interpretar e a utilizar quadros tecnológicos mais sofisticados, explicando, passo a passo, o seu funcionamento. Ele tem assunido esta perspetiva e, por vezes, de modo excessivo, raramente funcionando como um interface, um painel de respostas, concebido para permitir progressões pedagógicas ou a aproximação a ciclos de actividades.

Aquilo que se chama de transfert, a possibilidade de deslocação do conhecimento para outro conhecimento e a partir daqui, a evolução para um grau de complexidade da tarefa, pode contrariar o chamado de conhecimento inerte, portanto, conhecimento pouco aplicável a situações reais, com matriz muito teórica. O ME está mais direcionado como auxiliar do próprio professor, na planificação das matérias, na estruturação das suas aulas frequente o ME apresentar indicações e propostas de planificação de aulas - não possibilitando a organização de temas relacionados com outras disciplinas, ou pelo menos, dificultando a resolução de situações mais complexas, enriquecendo o pensamento e a aprendizagem (AUSUBEL, 2003).

Aliás, também, Edgar Morin (2002) tem consciência da dificuldade que existe quando a articulação curricular não é ativa, pois sendo o homem um ser, simultaneamente, físico, 
biológico, cultural, social, esta unidade complexa "está completamente desintegrada no ensino, através das disciplinas" (MORIN, 2002, p.17), pois que elas "impossibilitam colher o que está tecido em conjunto, o mesmo é dizer, segundo o sentido original do termo, o complexo" (MORIN, 2002, p.45). Ora O ME, raramente, soube suplantar a hiperespecialização, que "impede ver tanto o global (que fragmenta em parcelas), como o essencial (que dissolve)" (MORIN, 2002, p.45).

A estratégia de conceção de um ME deveria passar por todos estes aspetos e estabelecer compromissos com a aprendizagem autêntica e não, com simulacros de aprendizagem, elaborando cenários de probabilidades e improbabilidades, queremos dizer, determinar condições de aquisição em função de contextos, numa dialógica entre fins e meios. Nem todos os alunos são iguais, nem todas as turmas são homogéneas na sua constituição, nem todos os professores desenvolvem as mesmas estratégias de ensino e, portanto, nem todos os alunos aprendem da mesma maneira, pelo que, se desejamos liberdade e igualdade de aprendizagem estaremos diante de uma circunstância complexa, pois "a liberdade tende a destrutir a igualdade; esta, se é imposta, tende a destrutir a liberdade" (MORIN, 2000, p.97). Se as matérias, em si mesmas, não têm uma grande importância, então é no processo transfert que se deverá colocar a tónica da evolução, tomando nota da identidade de substância, quer dizer-se, o estudo da geometria facilita o estudo da lógica, o estudo da música facilita o estudo da matemática e, assim, sucessivamente.

Dá-se, desta forma, a amplificação do transfert de aprendizagem, cumprindo-se princípios de transfert inter-tarefa, em que "o material significativo é registado de forma redundante, de modo que se alguma parte for esquecida, pode reconstruir-se a partir do restante" (SIMON, 1981, p. 181). Se pelo contrário, o processo de ensino e aprendizagem, por resolução de problemas foi movido, principalmente, por objectivos "dará a impressão de trabalhar para trás, a partir do objectivo desejado; se for, principlamente, povido por estímulos, parecerá funcionar para a frente, partindo dos seus conhecimentos em direcção ao objectivo" (SIMON, 1981, p.183). Regressamos, novamente, à aprendizagem significativa de Ausubel, em que a existência de subsensores é primordial para a evolução do aluno. 0 ME tem esta dificuldade de criação de campos semânticamente ricos, preferindo, as frases 
curtas, as definições precisas, os comentários definitivos, os resumos que dão muito jeito. Para o aluno, mas também, para o professor.

Este quadro leva-nos a visitar a presença de feromonas, estímulos químicos que provocam respostas específicas ou mudanças comportamentais nos animais, incluindo o homem, donde, etimologicamente, se verifica que pherin (transferir) e hormona (excitar). Assim, quase que diríamos que um bom ME deveria expelir as suas feromonas, em termos dos seus organizadores mais determinantes, como potencial para influenciar o comportamento dos alunos, face ao seu ME, facilitando a transferência de conhecimentos e a facilitação da resolução de problemas. Se a vida humana e as suas interações, estão influenciadas pela existência de feromonas, então, com facilidade, poderíamos concluir que o ME deveria causar ao aluno, reações fortes, por acumulação sensorial ou por evocações particulares, antepondo ao sentido de prótese escolar, o fundamento de benefício educativo pleno.

Com alguma graça, Planchard afirma que "o livro escolar é um guarda-comidas" (1974, p. 383), compreendo-se a asserção, pelo facto de ele incluir quantidades de informação, fornecendo aos alunos, sob forma condensada, as matérias que devem ser aprendidas, do ponto de vista oficial, cometendo-Ihe "um carácter estático". E o problema não reside na quantidade de informação a transmitir, mas sim, na sua qualidade. A problemática não está nos conhecimentos que o aluno recebe, mas sim, como os sabe aplicar. E o receio avoluma-se, quando se verifica que os alunos seguem, à risca, a estrutura do manual e as considerações do professor sobre ele, representando, ainda por cima, processos inferiores de memorização (cf. Ausubel sobre retenção significativa). Existe, pois, um processo acanhado de aprendizagem. Há preocupações por parte dos autores e editoras no sentido de dar mais ênfase à forma de apresentação das matérias, do que uma cuidado na estimulação do pensamento. O ME, provavelmente, continuará a ser necessário, mas se o mal é muitas vezes real, "não é imputável ao livro como tal, mas antes à sua composição defeituosa, ao mau uso que dele se faz, à sua dissociação artifical dos outros instrumentos de formação" (PLANCHARD, 1974, p. 386). Se, em alguns casos, o ME pode substituir o professor, "é preciso saber quando e como. Tudo isso só poderá vir a realizar-se se os livros forem bem escolhidos e a se a sua apresentação corresponder aos interesses e aos desejos 
da criança, se a sua estrutura se adaptar às suas possibilidades psicológicas" (PLANCHARD, 1974, p. 387).

O desenho dos programas curriculares e a produção manualística estão, intimamente, ligados, pois no quadro vigente, de dependência do processo de ensino e aprendizagem da utilização do $\mathrm{ME}$, há que encarar esta problemática como central para o sucesso educativo, mais do que escolar. Hoje são muitas as preocupações à volta do ensino e da aprendizagem, o envolvente circundou as atividades de escola, colocando-lhes novos problemas, a que se há-de dar resposta conveniente. As práticas educativas e a organização escolar têm sido chamadas a dar resposta a circunstâncias educativas específicas, seja a turmas de alunos com dificuldades educativas acrescidas, classes de recuperação, ou para fazer face à individualização pedagógica.

Então, surge o debate sobre como dar resposta a estes problemas e como desenhar um mapa de atuação, conciliando programas, manuais, atividades de recuperação, avaliação interna e externa. A programação será, pois, uma tarefa ardilosa e delicada, que terá de ser definida minuciosamente, não por indicações breves e vagas, mas pela combinação de unidades curriculares sequênciais. Aqui, o ME deverá saber integrar-se nesta perspetiva, revelando-se dispositivo aberto, sereno e sustentável e que deixe de fora a tentativa de armazenamento de informação, sem que isso fragilize o modo de aprender e que, num processo de input e output se afaste, definitivamente, da ideia de um guarda-comidas (Planchard) ou de uma caixa de ferramentas (Chopin).

\section{Trofalaxia}

Por vezes, caímos na tentação de pensar que num ME deve caber tudo, uma quantidade interminável de informações, de comentários e sugestões sobre a variedade temática a que os programas fazem apelo, que deve constituir panaceia para todas as dúvidas escolares e que, por fim, os alunos estarão mais estimulados e alimentados. É o equívoco que bate à porta, porque elaborar uma didática completa e racional sobre todas as matérias de um programa, é tarefa gigantesca que um ME não pode suportar na sua estrutura, nem sabemos, se tal seria essencial. Seria relevância didática que o ME pudesse por um processo de transfert, passar feromonas para o aluno, provocando-o para a sua 
leitura e, afinal, apropriação dos seus conteúdos. Mas, normalmente, acontece essa passagem por um processo próximo da trofalaxia, um mecanismo de passagem de alimento de um indivíduo para outro, de modo direto, por uma mecânica de regurgitação.

Pode vir a tornar-se tirânico esse modo de transmissão de conhecimentos, porque não se revela estimulante, não permite a aplicação dos conhecimentos e não sensibiliza para a leitura de outras obras, que não as, estritamente, escolares, embora reconhecendo-se que se trata de uma mecânica biológica, tão importante para a conservação das espécies. Estaremos, provavelmente, diante de um caráter de mimetismo trofaláxico, em que o $\mathrm{ME}$ não se sabe se é uma ferramenta, um dispositivo, uma caixa, ou um livro. E é neste contexto, mais do que semântico, que se verifica um campo de recognição essencial para o aprofundamento da utilidade de um bom ME.

E o apelo que ele deve fazer à leitura é um dos prováveis esteios que o livro didático deve perseguir, para além, claramente, dos aspetos específicos de determinada matéria, seja ela de natureza científica, humanista ou artística. Ler, consiste, de uma forma genérica, no estabelecimento de relações entre sinais gráficos, objetos e ideias, num percurso inventariativo de conformidades e afinidades que, frequentemente, se quedam por preocupações fonéticas e rítmicas, revertendo numa forma de leitura que poderemos apelidar de inferior. Mas saber ler, que um ME deveria proporcionar por princípio, é um sentido superior de leitura, é compreender bem o que se lê, na base de fatores afetivos e operacionais. Verifica-se, contudo, que o ME é escrito numa linha simplista, esquemática, com definições curtas e muito apoiado na imagem, o que, em muitas ocasiões, devendo ser a linha construtiva, não deve, contudo, instituir um hábito de construção e semelhante em todos os manuais escolares, sejam eles de diferentes disciplinas.

Não há dúvida que nenhuma aprendizagem escolar se pode suportar na ideia básica de que não se podem ou devem controlar os resultados obtidos e que ao professor se the colocam dificuldades ao nível da modificação das suas estratégias educativas. Ora acontece, que tal iniciativa é dificultada ao professor, claramente, pela utilização em excesso do $\mathrm{ME}$, porque lhe está amarrado, quase como um instrumento protésico, dificultando o abraço a outras perspetivas de ação. Mas quando se pretende problematizar a pedagogia da leitura, por arcos criativos, deparamo-nos com a pobreza do vocabulário, da organização 
morfológica e numa impossibilidade de os textos de um ME dificilmente circularem num tempo dialógico, entre o plano formal e o plano contextual, resultando um ponto de vista linguístico frágil, funcional e momentâneo.

Em muitos dos manuais escolares, sem desejar generalizar, mas porque estamos ancorados em análises empíricas de alguma manualística escolar, a rarefação de conectores linguísticos podem conduzir à instabilidade do discurso e, portanto, à dificuldades de se poder mobilizar o aluno para um tipo de leitura proativa e proeficiente. A prática da leitura não se inicia na escola, está muito aquém desse lugar, o aluno, antes da sua entrada na escola, já tem um contacto com o circundante, tem experiências de vida e isso, irá refletir-se na leitura e na interpretação das palavras e frases escritas. Paulo Freire (2008, p.11) acreditava que " a leitura do mundo precede a leitura da palavra, daí que a posterior leitura desta não possa prescindir da continuidade da leitura daquele. Linguagem e realidade se prendem dinamicamente", ideia que Helena Martins (1986, p.14) reforçava, quando postulava que "enfim, dizem os pesquisadores da linguagem, em crescente convicção: aprendemos a ler lendo". Eu diria vivendo.

Assim, deseja-se que o ME escolar possa mobilizar o aluno para uma boa prática da leitura, na sala de aula e fora dela, pelo ME, mas também, pelos jornais e revistas, livros temáticos, enciclopédias, dicionários, a fim de aperfeiçoar a relação textual com o mundo. Não se pode confinar a leitura ao uso rotineiro do $\mathrm{ME}$, porque limita-se o âmbito da ação e do conhecimento, devendo-se diferenciar o género e o suporte, na singularidade daquela paráfrase, de quando a criança chega a casa e exclama satisfeita, gritando, mãe, já sei ler em qualquer lugar. Lembre-se que, na maior das vezes, o ME é o primeiro livro que entra em casa de uma família, pelo que, por maioria de razão, ele deverá revelar-se como um autêntico livro.

É natural que, hoje em dia, se encontrem concorrentes sérios ao prazer da leitura através de um livro, como é o caso da internet e de todas as possibilidades que ela concede ao indivíduo, permitindo a construção de objetos e imagens que favorecem a leitura. Contudo, há que estabelecer regras para a sua utilização e uma explicação sábia do que ela representa como ferramenta de pesquisa, de mediação para o estudo, de recreação, de complemento educativo e que pode, seguramente, gerar novos ambientes de 
aprendizagem. Mas também, o ME deve saber articular-se com aquela rede e saber como a há de potenciar como seu complemento. "A leitura tem de dar sentido ao mundo, assim, como as nossas aulas" (LAJOLO, 2002, p. 15), sendo que o ME se deverá enquadrar neste perspetiva, que é dinâmica e significativa. Caso contrário, estaremos confrontados com um dispositivo dispensável e, mesmo, inútil, porque não facilitará a aproximação do aluno à realidade, nem se tornará cúmplice na tarefa de conquista, não só, do saber, mas de um melhor saber.

Porque do que se trata quando se utiliza um ME é, também, de um desafio à sedução do aluno para o prazer de ler, não de um modo escolarizado, mas aberto e alargado a influências. Esta é uma aposta da escola e ela assume-se com maior risco ou gravidade, quando os professores optam, em muitos dos casos, insensatamente, por este ME e não por aqueloutro. Este é um campo de investigação, ainda, por desbravar, a escolha do ME em função, não simplesmente, da matéria científica em apreço, mas também, porque ele é o caminho para o sentido da leitura, não isolado da sua disciplina, mas na identificando da interação dessa especialidade com outras áreas do saber. Planchard (1974, p.410) volta à questão dos livros didáticos e dos fatores que fazem dele ou bom ou mau dispositivo didático, como "explicações teóricas exageradas para os alunos fracos, abuso do trabalho mecânico, antecipação da matéria...", concluindo-se que os manuais são, frequentemente, mal concebidos e adaptados ao perfil dos alunos e, portanto, ao perfil da nossa escola, recolocando-se, a cada momento, questões tão importantes, como "respeitar e desenvolver a individualidade, como adaptar as lições aos interesses mutáveis" (PLANCHARD, 1974, p. 434).

Se nos acercarmos do pensamento de Ilya Prigogine (1996) e sobre Os Fins das Certezas, verificamos que nos urge uma outra atitude sobre a adopção excessiva de um $\mathrm{ME}$, não bastará uma ação no sentido da desconstrução de uma determinada concepção de dispositivo, mas adquirir a suficiente consciência de que o professor ficará a ser uma espécie de joguete nas mãos dos grupos editoriais. Se não se souber tomar as posturas certas em termos daquilo que é o mais importante para o ato educativo, se não se contiver esse determinismo obsessivo que conduza ao fim das certezas dogmáticas, correr-se-á riscos de termos em mãos, de alunos e professores, um artefacto pré-fabricado de valor inferior, só 
porque, não soubemos combater as nossas certezas e fazer disso, um ato de opção entre o objeto e o sujeito.

O formalismo em que o ME se transforma quando aplicado na base da sua estrutura, fragmentado em unidades, relativamente, independentes, uma das outras, tende a transformá-lo num objeto autoritário, quando utilizado em idades não avançadas, como é o caso dos 20 e 30 ciclos de escolaridade. Assim, é preferível que o ME, no seu ato primeiro de construção seja tratado a partir de um universo alargado de significações, não limitado à sua base estrutural, estabelecendo relações com diferentes referências que the confere substância e coerência educativa significativa. Assim, estaremos perante um dispositivo de sinal referencialista que, obviamente, conduzirá o aluno a novas e inesperadas aquisições curriculares. Poucos são os manuais escolares que adotam este último perfil construtivo e que poderemos encontrar, por exemplo, em alguns espécimes de natureza temática. Desta forma, as finalidades de um ME esboça-se no sentido da criatividade contribuir para o desenvolvimento do aluno, tanto no campo emocional, social ou no do cognitivo.

Dificilmente, poderemos concluir, de modo definitivo, qual o futuro para o $M E$, em face de ele, ainda, estar no agrado de muitos dos docentes, ter favores políticos e os grandes grupos editoriais encontrarem, nele, uma indústria fluorescente, na ótica de serviço público, mas mais dificilmente, de serviço ao público. Se não estamos diante de uma máquina de ensinar, pelo menos, trata-se de um modo seguro e uniformizador de aplicar a divulgação de conhecimentos. Entretanto, reconhece-se que "tous les manuels ne sont pas négligeables sur le plan de l'information et de la méthode et, surtout, que les enseignants suffisamment actifs pour les abandonner ne sont pas en majorité ${ }^{\prime \prime}$ (MIALARET, 1981, p.196). Seguiremos na ideia de o ME deve interpretar o estudo da maneira como somos, como nos organizamos, como nos emocionamos e como (re)apresentamos as nossas identidades pessoais e coletivas através das nossas memórias. E que, fundamentalmente, o manual consiga desvalorizar a memória mecanizada, como rotina de ensino e de aprendizagem.

Contudo, segue-se, ainda, uma longa análise sobre o ME como objecto, como constructo, como dispositivo de educação, não perdendo de vista o produto escolar que ele

\footnotetext{
2 “Nem todos os manuais são negligentes em termos de informação e de método, e, sobretudo, os professores, em sua maioria, não estão suficientemente aptos para abandoná-los". (Trad. sugerida por Sandra Baldessin).
} 
é, no entanto de natureza carismática, rotineiro na sua utilização, que parece congelar a sua ciência ou o modo como apresenta a ciência. Mas é necessário ir um pouco mais longe do que aquilo que tem acontecido até ao presente, e perceber que ele se mantém, somente, à tona de água, porque é um facilitador das transposições didáticas e porque, principalmente, ajuda a reproduzir o modo como a escola se prepara e prepara os alunos, numa dinâmica de competências de curta duração. Revela-se a existência de uma espécie, através da utilização do $\mathrm{ME}$, de integração moral e social, que monopoliza a ação, consolidando a fragmentação disciplinar, as delimitações de território e a permanência, conveniente, da gestão curricular a nível nacional. O código serial de que o ME se constrói, vai de encontro à compartimentação das matérias, à formação especializada da maior parte dos docentes, ao vigor na utilização da sala de aula como recurso essencial da escola e às exigências burocráticas do sistema educativo. Estamos diante, de facto, de um poderoso recurso educativo que combate, no entanto, a natureza integrativa que qualquer processo de ensino e aprendizagem deve exigir.

O manual escolar como discurso pedagógico é uma gramática, que deve produzir mensagens, pois, como qualquer dispositivo pedagógico, constitui-se em "una gramática que regula lo que procesa: una gramática que ordena y posiciona y contiene también el potencial de su própria transformación ${ }^{3 \prime \prime}$ (BERNSTEIN, 1997, p. 195) e, portanto, a sociologia da educação deveria levar em linha de conta o dispositivo pedagógico, como regulador de relações, porque é terreno crucial "para las luchas por el control ". Afinal, também através do $\mathrm{ME}$ se podem reconhecer as lutas políticas e corporativas, alguns preconceitos ideológicos, interesses comerciais e autorais, evidências de uma cultura escolar ao serviço de interesses particulares.

Por fim, não se pode abandonar a ideia de que um ME não possa ser um livro de leitura, na tradição do que estamos habituados, de que não possa emocionar na sua organização frásica, de que não possa deixar de constituir referências particulares de escritas, seguindo a ideia fulcral de Roger Chartier (2008, p. 19), “je m'efforcerai de

\footnotetext{
3 “uma gramática que regula aquilo mesmo que processa: uma gramática que classifica e posiciona, e contém, também, o potencial de sua própria transformação". (Trad. Sandra Baldessin).

4 "lutas pelo poder"
} 
compreendre quelle place a tenu l'écrit dans la production des savoirs, dans l'échange des émotions et des sentiments, dans les relations que les hommes ont entretenues les uns avec les autres, avec eux-mêmes ou avec le sacré ${ }^{5 \prime}$. Por aqui, alcançaremos, com facilidade, a oportunidade dos versos de Quevedo (in Roger Chartier, 2008, p. 15) "Escuchar a los muertos com los ojos ${ }^{6 \prime \prime}$. E, afinal, deixámo-lo afogar no grande rio da aprendizagem, ou atamos-lhe uma pequena guita, para que se mantenha, sempre, à tona e com possibilidade de o trazermos até nós, como uma parte de nós?!

\section{Referências}

AUSUBEL, D. Aquisição e Retenção de Conhecimentos: uma perspectiva cognitiva. Trad. de Lígia Teopisto. Lisboa: Plátano, 2003.

BERNSTEIN, B. La estrutuctura del discurso pedagógico. Madrid: Edições Morata, 1997.

CHARTIER, R. Écouter les morts avec les yeux. Paris: Collège de France/ Fayard, 2008.

FREIRE, P. A importância do ato de ler: três artigos que se completam. 49 ed. São Paulo: Cortez, 2008.

LAJOLO, M. Do mundo da leitura para a leitura do mundo. 6 ed. Rio de Janeiro: UFRJ, 2002.

MARTINS, M. H. O que é leitura. 7 ed. São Paulo: Brasiliense, 1986.

MIALARET G. Histoire Mondiale de l'Éducation. Paris: Presses Universitaires de France, 1981.

\footnotetext{
5 "Esforço-me para compreender que o lugar da escrita, na produção do conhecimento, se dá na troca de emoções e sentimentos, nas relações que o homem estabelece consigo mesmo, com o seu semelhante e com o sagrado" (Trad. Sandra Baldessin).

6 "Escutar os mortos com os olhos".
} 
MORIN, E. Os Sete Saberes para a Educação do Futuro. Trad. de Ana Paula de Viveiros. Lisboa: Horizontes Pedagógicos, 2002.

PLANCHARD, É. A Investigação em Pedagogia. Coimbra: Arménio Amado, Editor, Suc, 1974.

PRIGOGINE, I. La Fin des certitudes. Temps, chaos, et les lois de la nature. Paris: Éditions Odile Jacob, 1996.

SIMON, H. As Ciências do Artificial. Trad. de Luís Moniz Pereira Coimbra: Arménio Amado, Editor, Suc., 1981. 